\title{
Correction: Biocatalytic oligomerization-induced self- assembly of crystalline cellulose oligomers into nanoribbon networks assisted by organic solvents
}

Yuuki Hata ${ }^{1}$, Yuka Fukaya ${ }^{1}$, Toshiki Sawada ${ }^{1,2}$, Masahito Nishiura ${ }^{3}$ and Takeshi Serizawa*1

\section{Correction}

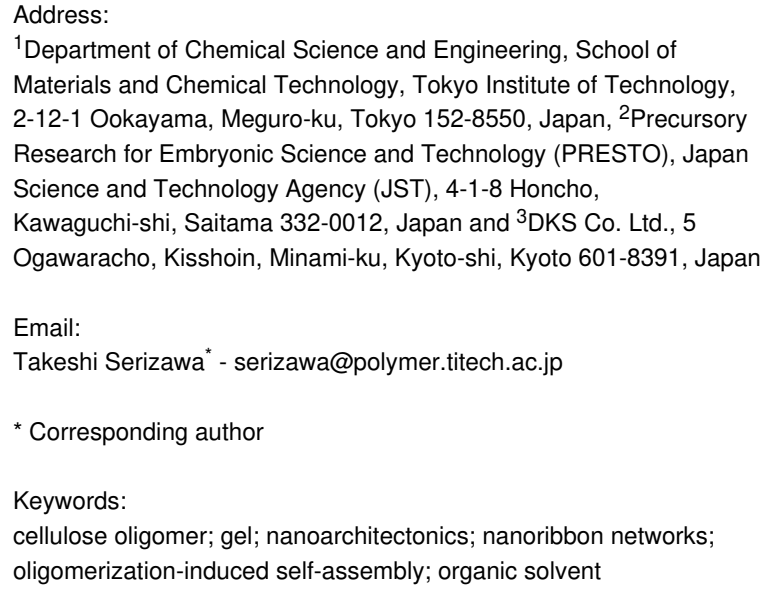

${ }^{1}$ Department of Chemical Science and Engineering, School of Materials and Chemical Technology, Tokyo Institute of Technology, 2-12-1 Ookayama, Meguro-ku, Tokyo 152-8550, Japan, ${ }^{2}$ Precursory Research for Embryonic Science and Technology (PRESTO), Japan Science and Technology Agency (JST), 4-1-8 Honcho,

Kawaguchi-shi, Saitama 332-0012, Japan and ${ }^{3}$ DKS Co. Ltd., 5

Ogawaracho, Kisshoin, Minami-ku, Kyoto-shi, Kyoto 601-8391, Japan

Email:

Takeshi Serizawa* - serizawa@polymer.titech.ac.jp

${ }^{*}$ Corresponding author

Keywords:

cellulose oligomer; gel; nanoarchitectonics; nanoribbon networks;

oligomerization-induced self-assembly; organic solvent


given below. 


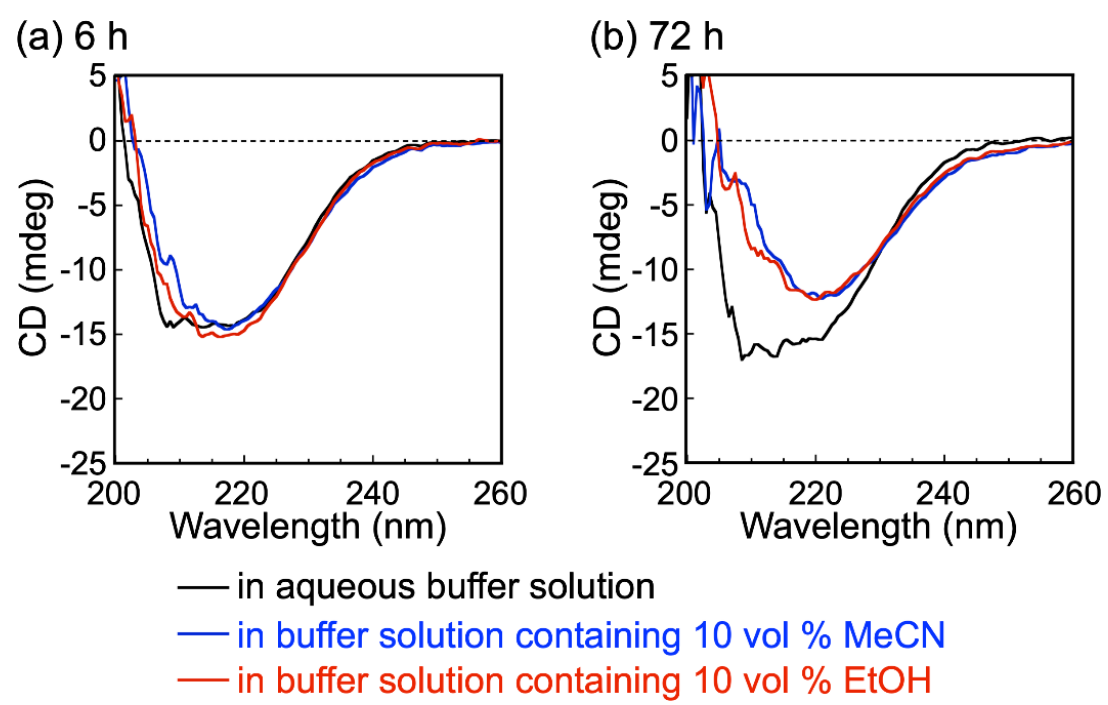

Figure 1: Corrected Figure 4 of the original publication.

\section{ORCID ${ }^{\circledR}$ iDs}

Yuuki Hata - https://orcid.org/0000-0003-1493-1896

Toshiki Sawada - https://orcid.org/0000-0001-7491-8357

Takeshi Serizawa - https://orcid.org/0000-0002-4867-8625

\section{License and Terms}

This is an Open Access article under the terms of the Creative Commons Attribution License (https://creativecommons.org/licenses/by/4.0). Please note that the reuse, redistribution and reproduction in particular requires that the authors and source are credited.

The license is subject to the Beilstein Journal of Nanotechnology terms and conditions:

(https://www.beilstein-journals.org/bjnano)

The definitive version of this article is the electronic one which can be found at:

doi:10.3762/bjnano.11.27 